\title{
Primer caso en la Región de Murcia [España] de linfoma anaplásico de células grandes asociado a implantes mamarios
}

\section{First case in region of Murcia [Spain] of breast implant-associated anaplastic large cell lymphoma}

Pablo J. VERA GARCÍA*, Ramón. A. MORENO VILLABA**

Clemente J. FERNÁNDEZ PASCUAL ${ }^{\star \star \star}$, Patricia REGO HERMIDA*

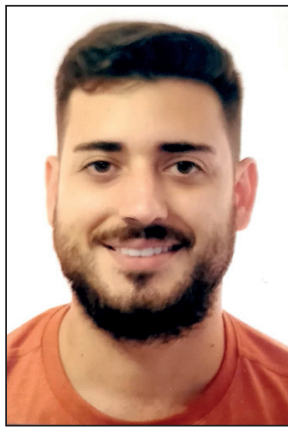

Vera García P. J.

\section{Resumen}

El linfoma anaplásico de células gigantes asociado a implantes mamarios es una entidad extremadamente rara de la que, hasta enero de 2019, han sido diagnosticados 656 casos en 34 países con 17 muertes comunicadas. Se postula que su etiología es el resultado de una reacción a un cuerpo extraño como la prótesis y la inflamación crónica persistente que se deriva.

Presentamos el primer caso de esta patología diagnosticado y tratado en la Región de Murcia, España. Se trata de una paciente con seroma crónico recidivante que aparece a los 5 años de la colocación de implantes mamarios tras diagnóstico y tratamiento por cáncer de mama. El diagnóstico definitivo se obtuvo en el estudio anatomopatológico e inmunohistoquímico de la cápsula periprotésica tras cirugía de retirada de implantes y capsulectomía completa bilateral. Se administró quimioterapia postoperatoria por recomendación del Comité de Tumores hospitalario.

Palabras clave $\begin{aligned} & \text { Linfoma anaplásico de células grandes, } \\ & \text { Implantes mamarios, Prótesis mamarias, } \\ & \text { Seroma tardío }\end{aligned}$
$\begin{aligned} & \text { Nivel de evidencia científica } \\ & \text { Recibido [esta versión] }\end{aligned}$
$\begin{array}{lr}\text { Aceptado } & \text { 5 Diagnóstico } \\ \text { 3 febrero/2019 }\end{array}$

\begin{tabular}{|c|c|c|}
\hline Key words & \multicolumn{2}{|c|}{$\begin{array}{l}\text { Breast implant-associated large cell } \\
\text { anaplastic lymphoma, Breast implants, } \\
\text { Breast prosthesis, Delayed seroma }\end{array}$} \\
\hline \multirow{3}{*}{\multicolumn{2}{|c|}{$\begin{array}{l}\text { Level of evidence } \\
\text { Received [this version] }\end{array}$}} & 5c Diagnostic \\
\hline & & 4 February2019 \\
\hline & & 3 September/2019 \\
\hline
\end{tabular}
3 September/2019

Conflicto de intereses: Los autores declaran no tener ningún interés financiero relacionado con el contenido de este artículo.

Financiación: No hubo fuentes externas de financiación para este trabajo.

\footnotetext{
* Médico Residente

** Facultativo Especialista Adjunto

*** Jefe de Servicio

Servicio de Cirugía Plástica y Quemados, Hospital Universitario Virgen de la Arrixaca, Murcia, España
}

Breast implant-associated large cell anaplastic lymphoma is an extremely rare entity of which, until January 2019, 656 cases have been diagnosed in 34 countries with 17 reported deaths. It's etiology is postulated as the result of a foreign body reaction to the implant and the resultant chronic and persistent inflammation.

We present the first case of this pathology diagnosed and treated in the Region of Murcia, Spain. A patient with chronic relapsing seroma that appears 5 years after breast implant placement after diagnosis and treatment for breast cancer. The definitive diagnosis was obtained in the pathological and immunohistochemical study of the periprosthetic capsule after implant removal surgery and bilateral complete capsulectomy. Postoperative chemotherapy was administered on the recommendation of the hospital Tumor Committee. 
La neoplasia de origen epitelial es la variante histológica más frecuente en el cáncer de mama. Las de origen no epitelial son raras, siendo más comunes las hematológicas (menos del 1\% del total), y destacando entre ellas el linfoma Hodgkin de células B. ${ }^{(1)}$

En 1985 se describe por primera vez el linfoma anaplásico de células grandes (LACG), ${ }^{(2)}$ entidad que en 1994 se englobaría en la categoría de Linfoma No-Hodgkin en la clasificación de neoplasias linfoides euroamericana ${ }^{(3)} \mathrm{y}$, en 2001, en la clasificación de neoplastias linfoides de la Organización Mundial de la Salud (OMS). ${ }^{(4)}$

La primera publicación en la literatura médica de un caso de LACG en una portadora de implantes mamarios, de la marca $\mathrm{McGhan}^{\circledR}$ (Inamed Corp, CA, EE.UU.) rellenos de suero y de superficie texturizada fue realizada por Kerch y $\mathrm{Creech}^{(5)}$ en 1997, despertando el interés por su principal particularidad, su asociación a prótesis mamarias. Desde entonces se han publicado varias series de casos diagnosticados, pero es interesante destacar que, en un último estudio de principios de 2019, hasta la fecha se ha alcanzado un recuento global mundial de 656 casos en 34 países, con 17 fallecimientos comunicados. ${ }^{(6,7)}$

A pesar de haber transcurrido muchos años desde el implante de las primeras prótesis de mama, que tuvo lugar en 1962, no fue hasta 2011 cuando la FDA ${ }^{(8)}$ publicó una alerta sanitaria debido a su preocupante asociación con una forma muy particular de Linfoma no Hodgkin. Finalmente, en 2016 la OMS decidió incluir al LACG asociado a implantes mamarios (LACG-AI) en la clasificación de tumores linfoides como una forma única de LACG que puede desarrollarse después de la colocación de implantes mamarios. ${ }^{(9)}$

Hasta el año 2016 no se documenta en revista científica el primer caso de LACG en México y América Latina, publicado por un cirujano plástico ${ }^{(10)}$ en esta misma revista. En España, en el marco del Sistema de Vigilancia de Productos Sanitarios, la Agencia Española de Medicamento y Productos Sanitarios (AEMPS) ha notificado 36 sospechas de LACG-AI, de las cuales hasta abril de 2019 se han confirmado 29 casos. ${ }^{(11)}$

El propósito de nuestro trabajo es dar a conocer el primer caso de LACG-AI diagnosticado y tratado dentro del sistema de salud público español en la Región de Murcia. Dados los pocos casos publicados en España y Latinoamérica creemos que nuestro trabajo puede aportar, además de conocimiento sobre el tema, más casuística bibliográfica e incentivo para la comunicación escrita de otros casos en nuestro ámbito nacional e internacional.
Paciente de 57 años de edad con numerosos antecedentes familiares de cáncer de mama por parte paterna: abuela, 3 tías-abuelas, 2 tías y 3 primas hermanas. Entre sus antecedentes personales destacan hipertensión arterial, diabetes méllitus tipo II y colitis ulcerosa, esta última sin tratamiento actual. Como antecedentes quirúrgicos, la paciente se había intervenido de colecistectomía, vagotomía y piloroplastia por ulcus duodenal e histerectomía.

En 2005 fue diagnosticada de cáncer de mama izquierda y sometida a cuadrantectomía súpero-externa de dicha mama y vaciamiento axilar, con posterior administración de quimioterapia de 6 ciclos según esquema TAC (docetaxel (Taxotere), clorhidrato de doxorubicina (Adriamicina) y ciclofosfamida) y radioterpia adyuvante. Tras estudio genético, fue diagnosticada portadora de la mutación del gen BRCA-1 (gen supresor de tumores cuya mutación se relaciona con cáncer de mama y ovario) por lo que se le realizó oforectomía bilateral profiláctica en 2008. Posteriormente, en junio de 2009 se llevó a cabo mastectomía subcutánea bilateral profiláctica, pexia mamaria, injerto libre areolar y colocación de implantes mamarios texturizados, marca Allergan ${ }^{\circledR}$, (Allergan Inc. Dublin, Irlanda) modelo ST-MF130-375cc. Tras sufrir dehiscencia de herida quirúrgica con exposición de prótesis mamaria derecha, fue intervenida de nuevo en julio de ese mismo año practicándosele desbridamiento quirúrgico y recambio de prótesis derecha por prótesis de marca también Allergan ${ }^{\circledR}$ modelo ST-410MF de $335 \mathrm{cc}$.

La paciente permaneció varios años asintomática, hasta que en diciembre de 2014 acudió a urgencias por dolor y aumento de volumen de la mama derecha tras realizar un esfuerzo físico, según refería. No había signos de infección ni de extrusión del implante y los hallazgos clínicos y ecográficos fueron compatibles con seroma tardío. No asociaba síndrome constitucional, fiebre, sudoración nocturna u otra sintomatología. En la exploración no se palparon adenopatías cervicales, supraclaviculares, axilares ni inguinales.

Tras varias consultas en urgencias por la misma clínica (dolor y aumento de volumen en mama derecha) en las que se pautó tratamiento antibiótico con amoxicilinaclavulánico, antinflamatorio y corticoide junto con medidas conservadoras como uso de sujetador deportivo sin aros, solo obtuvo una mejoría parcial de la sintomatología y fue diagnosticada en junio de 2015 mediante resonancia magnética nuclear (RMN) de contractura capsular de mama izquierda y seroma tardío en mama derecha (Fig. 1-4). 
En septiembre de ese mismo año fue intervenida quirúrgicamente de forma programada realizándose extracción de ambos implantes de mama y capsulectomía completa bilateral. El implante izquierdo presentaba rotura completa intracapsular y el derecho estaba íntegro, con seroma claro ambarino muy abundante y parcialmente organizado. En la misma intervención se llevó a cabo levantamiento de colgajo muscular de dorsal ancho sin isla cutánea para cobertura y protección de piel de mama izquierda previamente irradiada, y colocación de nuevos implantes texturizados, anatómicos, marca Polytech ${ }^{\circledR}$ (Polytech Health and Aesthetics GmbH, Dieburg, Alemania) de $375 \mathrm{cc}$ de volumen.

En el estudio anatomopatológico de la capsula protésica se detallan los siguientes hallazgos: “...en la superficie más interna de la formación capsular existe fibrina de forma abundante, que se encuentra entremezclada con una población significativa de células que muestran tamaño grande. Algunas de estas células grandes, poseen núcleos grandes de cromatina vesicular, con nucleolo prominente, identificando de forma escasa en algunas de ellas algunas mitosis típicas. Poseen, citoplasmas am-

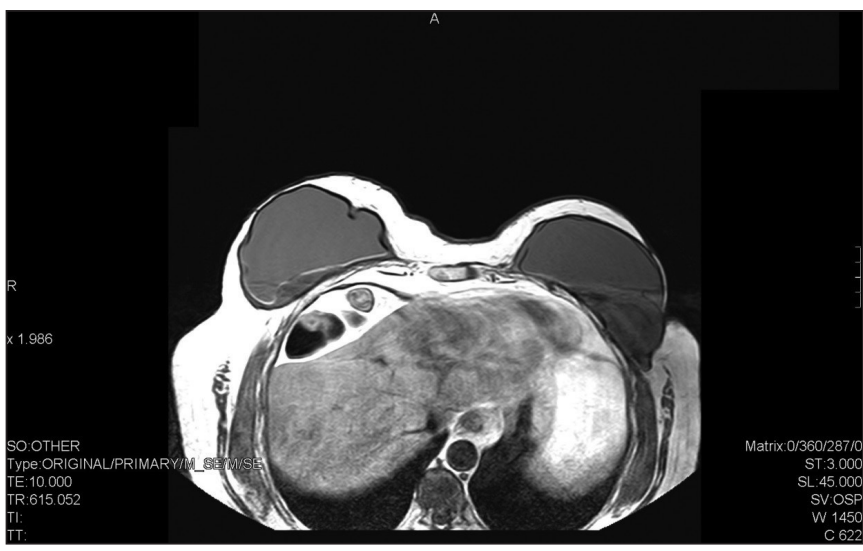

Figura 1. RMN torácica con contraste de corte axial a nivel de la región mamaria en secuencia T1. En la mama derecha predomina un seroma muy abundante y parcialmente organizado. El implante tiene un contorno irregular, con pliegues o rectificaciones. En mama izquierda, perdida de integridad de la prótesis con signo de lingüini o de la línea ondulante (colapso en distintos grados de la cubierta en el gel de silicona contenido por la cápsula fibrosa, mostrando múltiples líneas hipointensas curvilíneas) junto con ligero engrosamiento de la cápsula periprotésica compatible con contractura capsular.

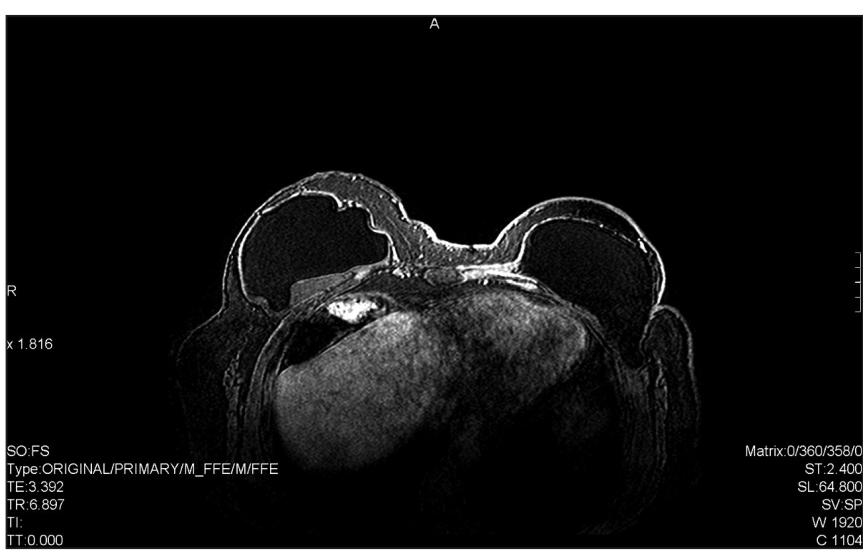

Figura 3. RMN torácica con contraste de corte axial a nivel de región mamaria en secuencia THRIVE. plios, anfófilos o de apariencia histioicitoide y a veces, muestran una disposición cordonal. El estudio inmunohistoquimico practicado revela: expresión intensa en esta población celular para los marcadores CD30, con expresión intensa nuclear para: BCL6. Ha mostrado resultados negativos para el resto de los marcadores testados, que han sido: $\mathrm{CD} 20, \mathrm{CD} 3, \mathrm{CD} 2, \mathrm{CD} 4, \mathrm{CD} 8, \mathrm{CD} 7, \mathrm{CD} 43$, CD45RO, EMA. Se identifica sobreexpresión, moderada/intensa para P-53, que se sitúan de forma visual, en torno a $+/-25-30 \%$. Decir, que la población de células "activadas" y/ o " atípicas" se sitúa, de forma predominante, en la porción más interna, y de forma mucho más mínima y focal, en el espesor de la capsula.

Los hallazgos morfológicos y resultados inmunofenotípicos arriba descritos, tienen que ser clasificados dentro del espectro de los Síndromes Linfoproliferativos CD30 $(+)$, aunque en el momento de la emisión de este informe estén pendientes aún de realizarse algunas técnicas inmunohistoquímicas, de las que solo se emitiría informe complementario adicional, si se identifican hallazgos patológicos relevantes a pesar de que haya identificado resultados negativos (no esperados) para algunos marcadores arriba

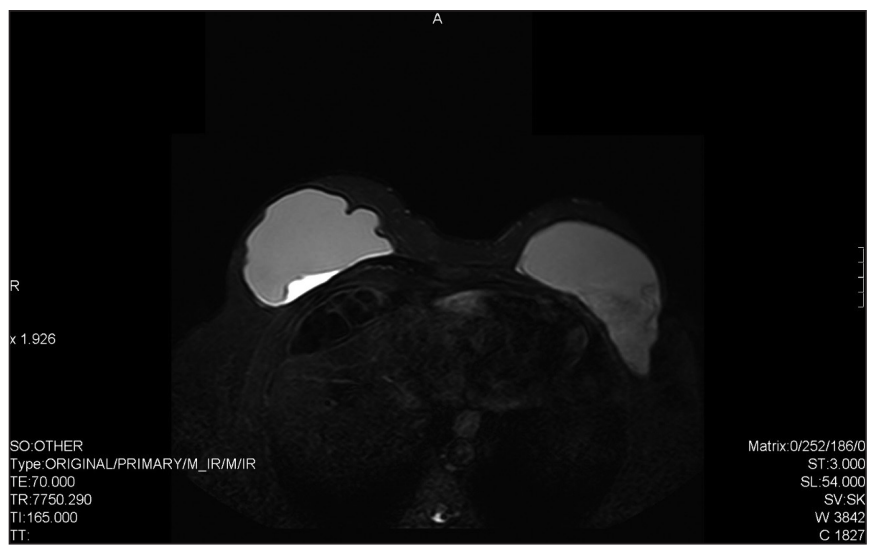

Figura 2. RMN torácica con contraste de corte axial a nivel de región mamaria en secuencia STIR.

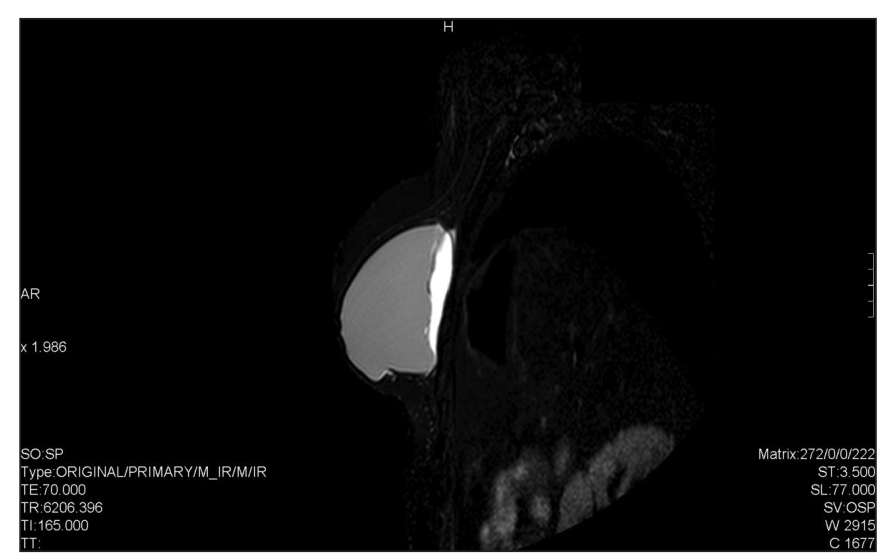

Figura 4. RMN torácica con contraste de corte sagital a nivel de región mamaria derecha en secuencia STIR. 
descritos como CD4, BCL2, etc, son sencuadrable dentro de la entidad anatomoclínica denominada en la literatura como Linfoma Anaplásico de Células Grandes ALK(-) Asociado a Implantes de Mama que, en la actualidad se considera una "entidad provisional" y que quizás tenga que ser de nuevo reclasificada por el comportamiento "indolente" que han mostrado muchas de las pacientes, comportamiento que se asemeja al subtipo de Linfoma Anaplásico Primario Cutáneo ALK(-)".

La paciente fue derivada a consulta de Oncología, que realiza estudio de extensión con PET-TAC cuyo resultado muestra: “...adenopatías paraesternales izquierdas de hasta $9 \mathrm{~mm}$ con ligero incremento metabólico, sin clara etiología de malignidad, pudiendo ser inflamatorio". Además, se realiza biopsia de la médula ósea con resultado negativo para malignidad.

Por último, la lesión fue diagnosticada como LACG-AI en mama derecha en estadio I - IPI 0, decidiéndose de manera consensuada en el Comité de Tumores de nuestro centro hospitalario (Hospital Universitario Virgen de la Arrixaca, Murcia, España) tratamiento con quimioterapia adyuvante según esquema $\mathrm{CHOP}$ (rituximab, ciclofosfamida, clorhidrato de doxorubicina (hidroxidaunorubicina), sulfato de vincristina (Oncovin) y prednisona) de un mínimo de 4 ciclos.

Cuatro años después de la cirugía, la paciente está asintomática y libre de enfermedad.

\section{Discusión}

Presentamos un caso de LACG-AI diagnosticado y tratado en el Hospital Clínico Universitario Virgen de la Arrixaca de Murcia (España), centro hospitalario de tercer nivel que atiende una población de 1.470 .000 habitantes dentro del Sistema Nacional de Salud en España. Creemos que su especial interés, dentro de lo que ya se conoce sobre esta patología, está en la descripción detallada de un caso más dentro de los pocos publicados desde España ${ }^{(1)}$ y entre los 29 que las publicaciones internacionales recogen en nuestro país. ${ }^{(6,7)}$

Se estima que el riesgo de padecer esta dolencia asociada a implantes mamarios está entre el 1:2832 para mujeres con implantes de poliuretano en Australia y Nueva Zelanda, el 1:30000 para mujeres con cualquier tipo de implantes texturizados en los EE.UU., y el 1:24000 en el Reino Unido, cifras obtenidas a partir de los datos de todos los implantes mamarios vendidos. Llama la atención la falta de consenso sobre la verdadera tasa de incidencia del LACG-AI, ya que varía en todo el mundo. Esto puede ser debido a un alto número de casos no detectados o a la infraestimada colocación de prótesis mamarias totales en todo el mundo. ${ }^{(13)}$ Lo que a nuestro juicio se puede decir es que, a la luz de las barreras antes mencionadas, la incidencia real de esta patología posiblemente esté subestimada. Con la aceptación y el conocimiento del LACG-AI como una verdadera entidad independiente de otros linfomas similares, y dado el elevado número de implantes mamarios colocados en el mundo, es probable que veamos un aumento importante en el futuro tanto en la detección de nuevos casos como en la presentación de nuevos informes sobre esta enfermedad. ${ }^{(6)}$

Los LACG-AI se caracterizan por un crecimiento anómalo de células $\mathrm{T}$ con un perfil inmunohistoquímico determinado: CD30+ y ALK-. ${ }^{(12)}$ Nuestro caso debutó con clínica de seroma crónico recidivante a los 5 años de la colocación de los implantes (2014). Hasta ese momento la paciente permaneció totalmente asintomática. En urgencias, para diagnóstico, se realizó ecografía de ambas mamas que confirmó la existencia de dicho seroma periprotésico en la mama derecha, sin signos asociados de rotura intra o extracapsular del implante. Para el tratamiento de urgencia se optó por la administración de antibiótico y antinflamatorios junto con medidas conservadoras; no se decidió llevar a cabo punción tras la mejoría inicial que presentó la paciente con estas medidas y por recomendación de los radiólogos, dada la escasa cantidad de liquido presente en el momento de la mejoría y el riesgo inherente de rotura del implante. Al año siguiente (junio de 2015), la paciente acudió de nuevo con clínica añadida de contractura capsular severa en mama izquierda y seroma en mama derecha. En esta ocasión se realizó estudio mediante RMN que confirmó ambos diagnósticos de sospecha.

Señalar que, las circunstancias especiales de este caso radican en que en los años de los que estamos hablando, el LACG-AI era una entidad rara y poco conocida, con escasa incidencia según los estudios publicados en ese momento. Es por ello que el diagnóstico definitivo de nuestro caso no llegó hasta el año siguiente tras la realización de la capsulectomía completa bilateral y estudio anatomopatológico con técnicas de inmunohistoquímica. La indicación quirúrgica vino dada por la necesidad de tratar la contractura capsular izquierda y el seroma crónico recidivante no respondedor a las medidas conservadoras pautadas con anterioridad, no por sospecha real de la entidad que aquí se discute.

En cuanto a la fisiopatología del LACG-AI, se cree que es resultado de una reacción a cuerpo extraño con la formación de cápsula fibrosa alrededor del implante mamario que precipitaría una cascada de reacciones inflamatorias mediadas por células y complemento, dando como resultado una activación de macrófagos, linfocitos y fibroblastos y formando una cápsula fibrosa. La persistencia de este cuerpo extraño puede desembocar en una 
estimulación prolongada de linfocitos, reacciones de hipersensibilidad tardía y con el tiempo, expansión clonal de las células Th1 y Th17. Al perpetuarse la inflamación crónica se siguen activando células $\mathrm{T}$ con la consecuente posibilidad de mutación de los oncogenes JunB y Satb1 en alguna línea celular que causa activación, independiente de los estímulos por antígenos para su crecimiento. ${ }^{(14)}$ Nuestra paciente es portadora de la mutación del gen BRCA-1, gen supresor de tumores cuya mutación se relaciona con cáncer de mama y ovario, y además cuenta con numerosos antecedentes familiares de cáncer relacionados con este gen.

Algún estudio ${ }^{(15)}$ propone que la infección crónica bacteriana del biofilm periprotésico provoca activación linfocitaria, hiperplasia y potencial malignización hacia un LACG-AI. Se ha llegado a aislar una bacteria, la Ralstonia spp, de forma más frecuente en las cápsulas de las pacientes con LACG-AI.

A nuestra paciente no se le practicó punción para extraer liquido de seroma periprotésico derecho dada la respuesta clínica que presentó inicialmente con el mencionado tratamiento conservador, además de por la falta de sospecha del LACG-AI. En ese momento existía poca repercusión de la patología en cuestión, lo que hizo que no estuviera desarrollada en nuestro hospital la metodología para su sospecha y diagnóstico. Finalmente, cabe recordar que el diagnóstico fue incidental al analizar anatomopatológicamente la cápsula periprotésica mamaria derecha tras la decisión de llevar a cabo una capsulectomía bilateral y retirada de los implantes. De forma intraoperatoria observamos la presencia de líquido claro ambarino como seroma mamario derecho, del que no se tomó muestra por la falta de sospecha de la entidad. El aspecto macroscópico de ambas cápsulas fue idéntico.

La diferencia principal entre los linfomas primarios de mama y los LACG-AI se encuentra en la localización del tumor; mientras que los linfomas primarios de mama pueden aparecer dentro del tejido mamario, a cierta distancia de la cápsula periprotésica, los LACG-AI surgen en el espesor de la misma o en el seroma periprotésico. ${ }^{(14)}$ Por tanto, los linfomas primarios pueden aparecer tanto en pacientes no portadoras de prótesis como en las que si las portan, mientras que los LACG- AI ALK(-)solo aparecen en las portadoras de implantes. ${ }^{(7)}$ En nuestro caso, ya en el informe del estudio anatomopatológico queda recogida en ese momento (año 2015) la necesidad de reclasificar la entidad "provisional" que era el LACG-AI, por el comportamiento indolente que presenta en muchas de las pacientes, asemejándose al subtipo de linfoma anaplásico primario cutáneo ALK(-), hecho que la OMS llevó a cabo en 2016 (Fig. 5).

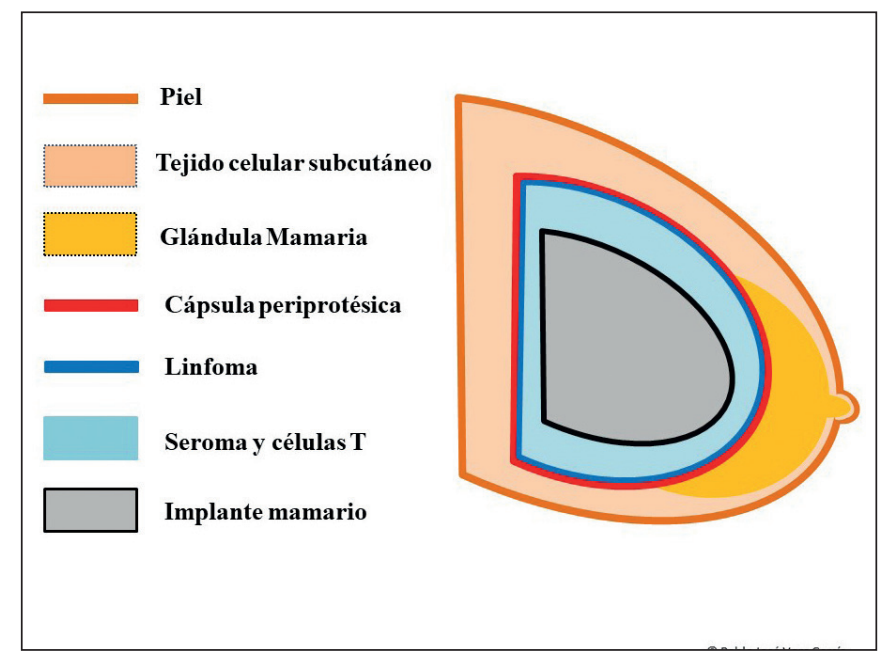

Figura 5. Esquema ilustrativo de la localización de las células tumorales respecto de la prótesis, cápsula y seroma periprotésico.

Centrándonos en la clínica, pese a que un porcentaje significativo de las pacientes en el momento del diagnóstico se encuentran asintomáticas, ${ }^{(1)}$ el LACG-AI tiene una presentación muy heterogénea. La clínica más frecuente es el aumento tardío de volumen de manera debido a la acumulación de líquido alrededor de la prótesis, lo que se denomina seroma periprotésico tardío, o menos frecuentemente como una masa pericapsular. (14,16) La intensidad del seroma puede ser variable, produciendo en algunos casos una clínica indolente que podría ser causa del retraso en el diagnóstico y tratamiento. El tiempo que transcurre desde la implantación de la prótesis hasta la aparición del LACG-AI es muy variable, desde los 4 meses a los 40 años, con una media de 9.3 años. ${ }^{(1,12)}$ En el caso que describimos, la presentación del LACG-AI no fue hasta pasados 5 años de la colocación de los implantes, momento en el que la paciente consulta por una clínica compatible, si bien hasta los 6 años no se realizó el diagnóstico definitivo. Algunos artículos describen que el retraso entre la aparición de los síntomas y el tratamiento se llegó a prolongar hasta 2 años sin que esto significara peor pronóstico para la paciente. ${ }^{(6,12)}$

El aspecto del seroma oscila entre claro ambarino hasta espeso, cremoso y particulado. ${ }^{(6)}$, En nuestro caso se trataba de un seroma claro ambarino. Menos frecuente es que el LACG-AI adopte la apariencia clínico-radiológica de los procesos agresivos de la mama, como masa palpable, ulceración de piel o adenopatías regionales con criterios sospechosos de malignidad. ${ }^{(1)}$ Los casos en los que apareció una masa pericapsular son los que presentaron evolución menos favorable con desenlace fatal en algunas ocasiones. ${ }^{(6)}$ Tras realizar en nuestro caso un exhaustivo estudio de extensión con métodos de imagen, no se hallaron signos de malignidad asociados tales como masas o adenopatías regionales. 
La clínica asociada descrita varía desde ninguna hasta la aparición de síntomas B (fatiga, pérdida de peso y sudoración nocturna), que no están presentes necesariamente en los casos de enfermedad diseminada. Nuestra paciente no presentó más sintomatología que la de dolor y aumento de tamaño de la mama derecha.

Está descrito que la mortalidad relacionada con la enfermedad por enfermedad infiltrativa llega al $40 \%$ en 2 años. ${ }^{(17)}$ No está del todo claro si la enfermedad in situ progresa a enfermedad infiltrativa o si se trata de dos entidades distintas que conllevan riesgos separados de diseminación. ${ }^{(18)}$

En cuanto a la etiopatogenia, tras revisar la bibliografía disponible, se pueden establecer como factores de riesgo a desarrollar LACG-AI la presencia de un biofilm subclínico en los implantes texturizados, la contractura capsular previa, una predisposición genética, una etiología autoinmune o una estimulación crónica de células $\mathrm{T}$ como mecanismos. ${ }^{(12,14)}$ Nuestra paciente era portadora de implantes texturizados marca Allergan ${ }^{\circledR}$ ST-410 MF de $335 \mathrm{cc}$.

En cuanto al tratamiento, es principalmente quirúrgico, precisando la retirada de la prótesis y la capsulectomía total además de la exéresis de las masas asociadas con comprobación de límites quirúrgicos sanos y de las adenopatías axilares sospechosas. En nuestro caso fue realizada la retirada bilateral de las prótesis, capsulectomía completa bilateral y posterior levantamiento de un colgajo muscular de dorsal ancho sin isla cutánea para cobertura y protección de piel de la mama izquierda previamente irradiada, finalizando con la colocación de nuevos implantes mamarios texturizados, anatómicos, pero de otra marca.

Tras el diagnóstico anatomopatológico final y el estudio de extensión, se recomienda seguir tratamiento complementario coadyuvante mediante radioterapia y quimioterapia en los casos de enfermedad avanzada. En nuestro caso, a pesar de no comprobarse diseminación de la enfermedad, el Comité de Tumores de nuestro hospital decidió llevar a cabo adyuvancia con quimioterapia.

El seguimiento medio de las pacientes de las que se tienen datos es de 18 meses con una tasa de recurrencia del $30 \%$, el $60 \%$ de los cuales se presentaron como una tumoración asociada en el momento del diagnóstico. Sin embargo, en el $92 \%$ de los casos cuya única presentación fue el seroma tardío, no se han encontrado recurrencias. Es por tanto una característica importante del LACG-AI su buen pronóstico tras la retirada de las prótesis mamarias. ${ }^{(1)}$ Nuestra paciente, tras 4 años de seguimiento postoperatorio, continua con controles seriados por medio de RMN y ecografía, sin que hasta el momento haya presentado recidiva.
En colaboración con la Fundación de Cirugía Plástica, la Sociedad Americana de Cirujanos Plásticos y la Food and Drug Administration en EE.UU. (FDA), se creó el proyecto llamado PROFILE (Patient Registry and Outcomes For breast Implants and anaplastic large cell Lymphoma (ALCL) etiology and Epidemiology) que pretende servir de registro de los casos de LACG-AI para ampliar los datos existentes y el conocimiento sobre la enfermedad, recogiendo estos datos tanto de forma retrospectiva como prospectiva (www. thepsf.org). ${ }^{(12)}$ La finalidad última de este registro es recomendar pautas de actuación para recogida de datos y comunicación de los mismos a nivel mundial en el entorno en el que trabajan los especialistas en Cirugía Plástica.

En España existe desde hace años un formulario de notificación de incidentes por parte de los profesionales sanitarios mediante el cual pueden comunicar a las autoridades sanitarias nacionales cualquier evento relacionado con medicamentos y dispositivos médicos, como son los implantes mamarios, y un formulario de información adicional de casos de LACG-AI que dependen del Ministerio de Sanidad, Consumo y Bienestar Social y la Agencia Española del Medicamento y Productos Sanitarios (AEMPS), y que se pueden encontrar en la siguiente dirección web: https://www. aemps.gob.es/vigilancia/productosSanitarios/vigilanciaprofesionales.htm

Por otro lado, la Sociedad Española de Cirugía Plástica, Reparadora y Estética (SECPRE) puso en marcha a finales de 2015 una Comisión Interna de Seguimiento del LACG-AI y puso a disposición de sus miembros un formulario y una dirección de correo electrónico, linfomas@secpre.org para la notificación de casos registrados por los especialistas en Cirugía Plástica, Reparadora y Estética a nivel nacional formulario de notificación adicional en el que comunicar y poner en conocimiento de la sociedad de profesionales de este ámbito nuevos casos a nivel nacional.

Cabe mencionar también la puesta en marcha en nuestro país, desde diciembre de 2017, de un Registro Nacional de Implantes Mamarios a través del cual se pretende registrar y conocer el número total de implantes mamarios colocados anualmente en España y así poder extraer datos reales y registro de incidencias. La dirección de este Registro Nacional es https://sreim. aemps.es

Adicionalmente, en febrero de 2019, la AEMPS ha desarrollado un protocolo clínico para la detección del LACG-AI destinado a todos los profesionales y centros sanitarios españoles implicados en la detección de casos de esta patología (Gráfico 1). ${ }^{(19)}$ 


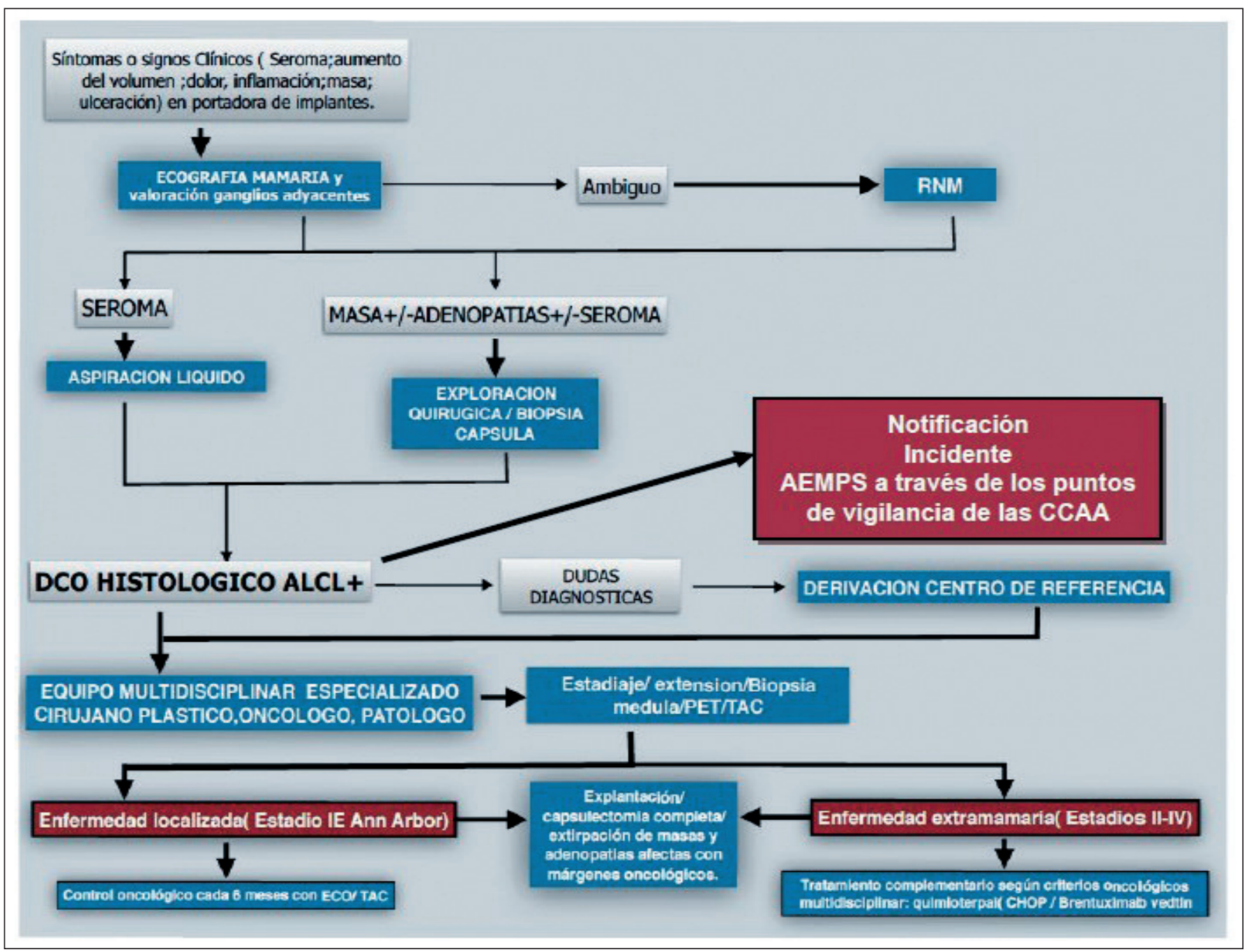

Gráfico 1. Protocolo clínico para la detección del LACG-Al. 6.2.2019. Disponible en: https://www.aemps.gob.es/vigilancia/productosSanitarios/linfoma-anaplasicoLACG/docs/Protocolo_Clinico_ALCL_implantes_mamarios.pdf

Presentamos el primer caso diagnosticado y tratado de LACG-AI en la Región de Murcia, España, en el Hospital Clínico Universitario Virgen de la Arrixaca. Nuestro interés, dentro de lo que ya se conoce sobre esta patología, es el describir detalladamente un caso más dentro de los pocos publicados y comunicados desde España y Latinoamérica, así como difundir las pautas de actuación para recogida de datos y comunicación de los mismos en el entorno en el que trabajan los especialistas en Cirugía Plástica en nuestro ámbito nacional.

\section{Dirección del autor}

Dr. Pablo José Vera García

Servicio de Cirugía Plástica y Quemados

Hospital Universitario Virgen de la Arrixaca

Carretera Madrid-Cartagena s/n

30120 El Palmar, Murcia, España

Correo electrónico: pablojvg2407@gmail.com
1. Fernández-Sobrino I, Cordones-Guerrero JJ, Benítez-Dupin O y col. Masa palpable como presentación atípica de linfoma anaplásico de células gigantes asociado a implantes mamarios. Cir. plást. iberolatinoam. 2017; 43(2): 129-135.

2. Stein H, Mason DY, Gerdes $\mathbf{J}$ et al. The expression of the Hodgkin's disease associated antigen Ki-1 in reactive and neoplastic lymphoid tissue: evidence that Reed-Sternberg cells and histiocytic malignancies are derived from activated lymphoid cells. Blood. 1985; 66(4): 848-858.

3. Harris NL, Jaffe ES, Stein $\mathbf{H}$ et al. A revised European-American classification of lymphoid neoplasms: a proposal from the International Lymphoma Study Group. Blood. 1994; 84(5):13611392.

4. Delsol G, Ralfkiaer E, Stein H, Wright D, Jaffe ES. Anaplastic large cell lymphoma. In: World Health Organization Classification of Tumours. Pathology and genetics of tumours of haematopoietic and lymphoid tissues. Jaffe ES, Harris NL, Stein H, Vardiman JW (Eds): IARC Press. Lyon, 2001, Pp. 230-235.

5. Keech JA Jr, Creech BJ. Anaplastic T-cell lymphoma in proximity to a salinefilled breast implant. Plast. Reconstr. Surg. 1997;100(2):554-555.

6. Collett DJ, Rakhorst H, Lennox P, et al. Current Risk Estimate of Breast Implant- Associated Anaplastic Large Cell Lymphoma in Textured Breast Implants. Plast ReconstrSurg. 2019;143(3S): 30S-40S. 
7. Miranda RN, Medeiros LJ, Ferrufino-Schmidt MC, et al. Pioneers of Breast Implant-Associated Anaplastic Large Cell Lymphoma: History from Case Report to Global Recognition. Plast Reconstr Surg. 2019;143(3S):7S-14S.

8. US Food and Drug Administration. Anaplastic large cell lymphoma (ALCL) in women with breast implants: preliminary FDA findings and analyses. Center for Devices and Radiological Health Silver Spring, MD. 2011.

9. Swerdlow SH, Campo E, Pileri SA et al. The 2016 revision of the World Health Organization classification of lymphoid neoplasms. Blood. 2016;127 (20):2375-2390.

10. Torres-Rivero C, Ramos-Gallardo G, Nambo-Lucio MJ, Vaquero-Pérez MM. Primer caso en México y América Latina de linfoma anaplásico de células gigantes en paciente con implantes mamarios. Cir plást iberolatinoam 2016; 42 (2): 175-180.

11. Agencia Española de Medicamentos y Productos Sanitarios AEMPS. Información sobre el linfoma anaplásico de células grandes asociado a implantes de mama. Ref: PS, 9/2019. Fecha de publicación: 4 de abril de 2019.

12. Clemens MW, Miranda RN. Breast Implant-Associated Anaplastic Large Cell Lymphoma After 18 Years of Investigation. Clin Plastic Surg. 2015, 42:605-613.

13. Fitzal F, Turner SD, Kenner L. Is breast implant associated anaplastic large cell lymphoma a hazard of breast implant surgery? Open Biol. 2019; 26, 9(4):190006.
14. Kadin ME, Deva A, Xu $\mathrm{H}$ et al. Biomarkers provide clues to early events in the pathogenesis of breast implant associated anaplastic large cell lymphoma. Aesthet Surg J. 2016; 36(7): 773781.

15. Hu H, Johani K, Almatroudi A et al. Bacterial biofilm infection detected in breast implant associated anaplastic large cell lymphoma. Plast Reconstr Surg. 2016; 137:1659-1669.

16. Clemens MW, Medeiros LJ, Butler CE et al. Complete surgical excision is essential for the management of patients with breast implant-associated anaplastic large-cell lymphoma. J Clin Oncol. 2016; 34 (2):160-168.

17. Kaartinen I, Sunela K, Alanko J, et al. Breast implant-associated anaplastic large cell lymphoma -From diagnosis to treatment. European Society of Surgical Oncology. 2017; 43(8): 1385-1392.

18. McCarthy CM and Horwitz SM. Association of breast implants with anaplastic large-cell lymphoma. JAMA Oncology. 2018; 4(3): 341-342.

19. Agencia Española de Medicamentos y Productos Sanitarios, AEMPS. Web. Protocolo clínico para la detección del linfoma anaplásico de células grandes (LACG) asociado a implantes de mama. 6.2.2019. Disponible en: https://www.aemps.gob.es/ vigilancia/productosSanitarios/linfoma-anaplasicoLACG/docs/ Protocolo_Clinico_ALCL_implantes_mamarios.pdf 